\title{
TRATAMIENTO QUIRURGICO DE LA INCONTINENCIA URINARIA DE ESFUERZO EN LA MUJER
}

\author{
Doctor Mariano Bedoya Hevia*
}

Actualmente el tratamiento quirúrgico de la incontinencia urinaria de esfuerzo en la mujer, cobra gran importancia debido al alto porcentaje de pacientes que acuden al especialista, portadores de este trastorno. Conociendo su gran trascendencia médico-social, es como gran número de ginecólogos se han profundizado en su estudio.

Haciendo un aval de nuestra experiencia, sostengo que uno de los puntos más importantes, al que tengo que referirme en el presente trabajo, es el que concierne al diagnóstico; para llegar a obtenerlo comenzamos por practicar un examen clínico completo, estudiando los antecedentes obstétricos, como son la multiparidad, partos distócicos y fórceps; el estudio del estado constitucional es de suma importancia; la exploración neurológica es imprescindible, y de manera muy particular en aquellas pacientes que son nulíparas, ya que la incontinencia está supeditada a un factor de ordinario nervioso, psíquico o tal vez urinario; el examen radiológico simple, para descartar espina bífida; la urogra- fía excretora, prueba vital de examen; la cisto-uretrografía, método valiosísimo, ya que gracias a él precisaremos las modificaciones del ángulo vésico-uretral posterior y en algunos casos hasta observaremos modificaciones más acentuadas, como el aspecto en embudo de la unión uretro-vesical. El examen ginecológico y urológico son de rutina.

Creo que una perfecta evaluación se hará principalmente considerando dentro del examen lo que se llama la "prueba de esfuerzo"; con esta prueba podemos precisar el diagnóstico y el tratamiento a seguir. Nuestra experiencia quirúrgica la voy a referir a la Técnica que más hemos seguido, y esta es la de Kennedy.

Esta intervención siempre la practicamos con anestesia local: Novocaína al $\frac{1}{2} \%$, en pacientes nerviosas recomendamos la anestesia general. Colocada la paciente en una buena posición, introducimos una sonda de Foley, sonda que la mantenemos en vejiga aproximadamente unos 4-5 días. Tomamos el cuello con un tenáculo, incidimos la pared

* Colmena 267 Lima, Perú. Profesor Principal de Ginecología, Facultad Medicina San Marcos. Julio de 1962 . 

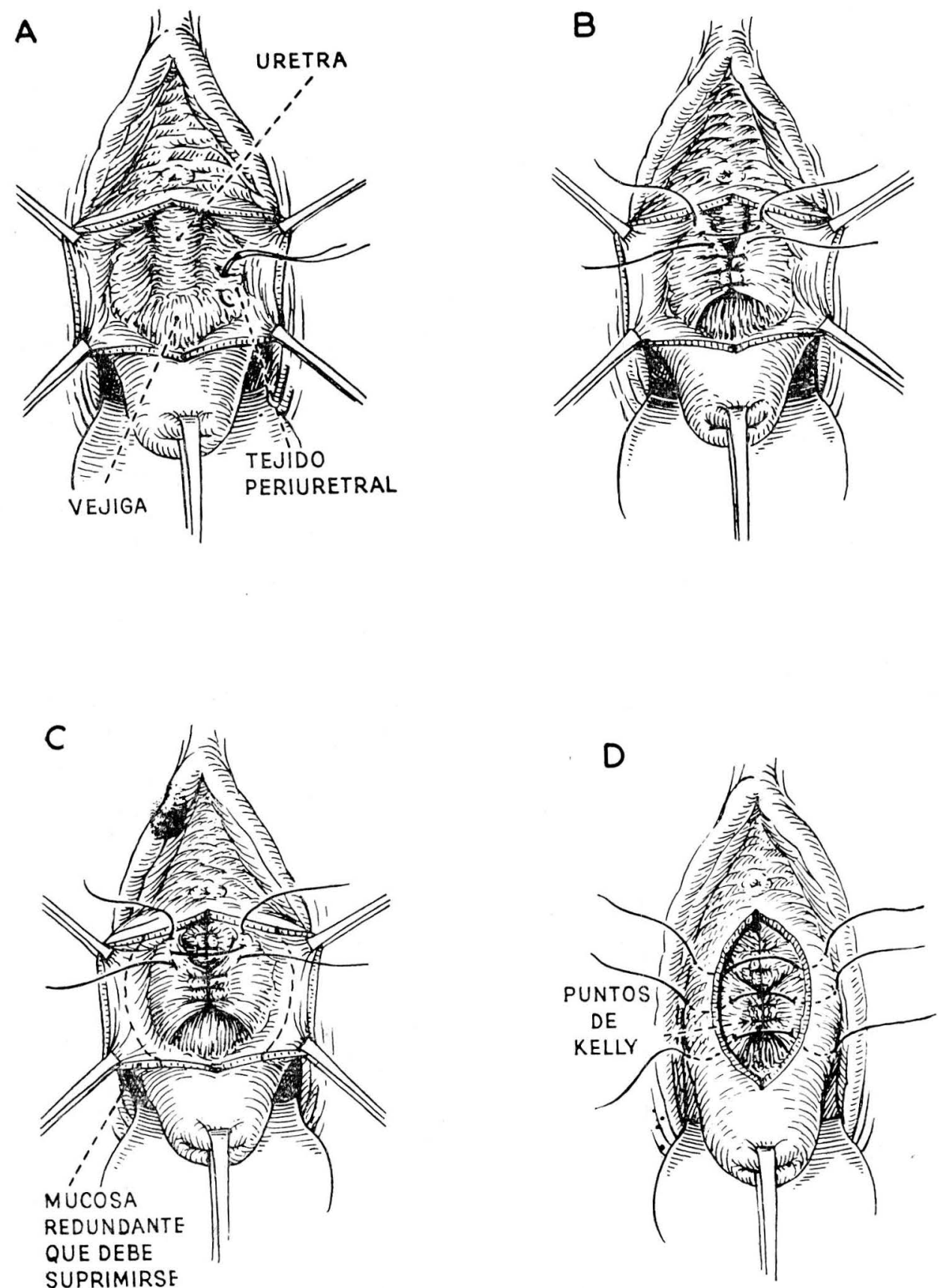
vaginal anterior en la línea media, desde $1,5 \mathrm{~cm}$ por debajo del meato uretral hasta $2 \mathrm{~cm}$ por encima del O.E. (fig. A). Luego movilizamos la uretra ampliamente evitando en lo posible herir el plexo venoso y la arteria vesical inferior. La plastia fascial la hacemos en tres planos; un primer plano (fig. AB) con catgut crómico número 1 , practicando puntos de colchonero; luego (fig. C) hacemos un segundo plano fascial, que trae como consecuencia el que la uretra permanezca más alejada de las ramas del pubis. Posteriormente colocamos un punto de Kelly, con lo que conseguimos fruncir la parte interna de la uretra, cerca del esfínter interno.

Para restaurar el esfínter voluntario, se comienza por resecar el músculo lesionado que queda pegado a la mucosa vaginal, suturando el resto con catgut más fino (fig. D) que atraviesa la pared vaginal, tratando de que los puntos interesen las fibras del constrictor de la uretra y la aponeurosis del diafragma.

Post-operatorio. En este período hacemos el tratamiento con antibióticos; retiramos la sonda al 4-5 día, jamás hemos tenido hematuria. Al retirar la sonda, la enferma orina espontáneamente $(95 \%)$. En un $5 \%$ de casos se ha tenido que colocar nuevamente la sonda por 1 día. El control de la orina residual lo hacemos por unos días. Las pacientes se levantan a los 4-5 días.

Resultados. En el lapso de diez años (1951-1960) hemos tratado 113 casos de incontinencia, con un promedio de éxitos inmediatos de 100\%; en controles posteriores el éxito alcanzado es de $94 \%$.

\section{$\begin{array}{llllllllllll}\text { B } & I & \text { B } & \mathbf{L} & \mathbf{I} & \mathbf{O} & \mathrm{G} & \mathbf{R} & \mathbf{A} & \mathbf{F} & \mathbf{I} & \mathbf{A}\end{array}$}

ARENAS N.: Gyn. y Obst. Rev. Vol. III, 1957.

BALL T. L. A.: American Journal Obst. \& Gyn., 1950.

BEDOYA M. : Tratamiento del Prolapso genital. 1er. Congreso de Gin. y Obst. Lima, Perú, 1959. GIL, VERNET: Incontinencia Urinaria en la Mujer, estudio clínico y tratamiento quirúrgico. 1955. KENNEDY: Amer. Jour. Obst. \& Gyn., 1937.

T. LINDE: Ginecología Operatoria. Segunda Edición. 